\title{
Electrical activity of intra-grain defects in polycrystalline silicon layers obtained by Aluminum-Induced Crystallization and epitaxy
}

D. Van Gestel ${ }^{\text {a) }}$, M. J. Romero ${ }^{\text {b) }}$, I. Gordon ${ }^{\text {a) }}$, L. Carnel ${ }^{\text {a) }}$, J. D’Haen ${ }^{\text {c,d) }}$, G. Beaucarne

${ }^{\text {a) }}$, M. Al-Jassim ${ }^{\text {b) }}$ and J. Poortmans ${ }^{\text {a) }}$

a) IMEC vzw, Kapeldreef 75, B-3001 Leuven, Belgium

b) National Renewable Energy Laboratory (NREL), 1617 Cole Blvd. Golden, Colorado 80401-3393

${ }^{c)}$ Hasselt University, Institute for Materials Research, Wetenschapspark 1, B-3590 Diepenbeek, Belgium

d) IMEC vzw, Division IMOMEC, Wetenschapspark 1, B-3590 Diepenbeek, Belgium

\begin{abstract}
Defect etching revealed a very large density $\left(\sim 10^{9} \mathrm{~cm}^{-2}\right)$ of intra-grain defects in polycrystalline (pc-Si) silicon layers obtained through aluminum-induced crystallization of amorphous Si and epitaxy. Electron beam induced current measurements showed a strong recombination activity at these defects. Cathodoluminescence measurements showed the presence of two deep-level radiative transitions $(0.85 \mathrm{eV}$ and $0.93 \mathrm{eV})$ with a relative intensity varying from grain to grain. These results indicate that the unexpected quasi-independence on the grain size of the open-circuit voltage of these pc-Si solar cells is due to the presence of numerous electrically active intra-grain defects.
\end{abstract}




\section{MAIN TEXT}

Minority carriers have a high probability to recombine at grain boundaries in pc-Si layers (defined here as layers with grain diameters of 0.1-100 $\mu \mathrm{m}$ ). Control over the average grain size and the grain size distribution is therefore important to obtain pc-Si films of sufficient quality for devices like thin-film transistors or solar cells. Aluminum-induced crystallization (AIC) in combination with epitaxial thickening allows obtaining columnar pc-Si layers ${ }^{1,2}$ on foreign substrates with different grain size distributions. ${ }^{3}$ Recently, we showed that solar cells made from pc-Si layers with very small grains of $0.2 \mu \mathrm{m}$ had almost the same open-circuit values $\left(\mathrm{V}_{\mathrm{oc}}\right)$ as solar cells made from AIC-based pc-Si layers with grain diameters of up to $50 \mu \mathrm{m} .{ }^{4,5}$ Since the $\mathrm{V}_{\mathrm{oc}}$ of thin-film solar cells is a measure for the electronic quality of the absorber material, the quasi-independence of the open-circuit voltage on the grain size indicates that grain boundaries and grain size distribution are not the only factors limiting the electronic quality of pc-Si layers. Moreover, intra-grain dislocations can be harmful for the electrical layer quality, and different models have already been proposed to describe their effect on the minority carrier lifetime and the Voc of silicon solar cells. ${ }^{6,7}$

In this letter we use defect etching-, electron backscattering diffraction (EBSD)-, Electron Beam Induced Current (EBIC)-, and Cathodoluminescence (CL) measurements to study the effect of intra-grain defects (IGD) on the electrical quality of pc-Si layers made by AIC in combination with epitaxial growth. 
We prepared AIC seed layers with large grain diameters up to $50 \mu \mathrm{m}$ to reduce the influence of grain boundaries on the measurements presented in this letter. ${ }^{4}$ After seed layer formation and before epitaxial growth, we removed secondary Si crystallites from the seed layer. ${ }^{4}$ We then epitaxially thickened the seed layers into p-type layers of $4 \mu \mathrm{m}$ thickness by chemical vapor deposition (CVD) at $1130^{\circ} \mathrm{C}$. After epitaxial growth, we passivated the pc-Si layers by plasma hydrogenation at $400^{\circ} \mathrm{C}{ }^{8}$

We polished the layers and used a slightly adapted Schimmel defect etch (1 (HF 49\%) : 1 $\left.\left(\mathrm{CrO}_{3} 0.7 \mathrm{M}\right)\right)$ to make the crystal defects visible. ${ }^{9}$ Afterwards, intra-grain defects were easily distinguishable from grain boundaries. The grains showed a very high IGD density of $\sim 10^{9} \mathrm{~cm}^{-2}$ (see Figure 1). The square shaped structures, the $\mathrm{U}$ shaped lines and the perpendicular lines in Figure 1 all result from epitaxial stacking faults along (111) planes when looking at a (100) plane. EBSD measurements verified that the grain in Figure 1 indeed has a (100) orientation. Most of the grains in our pc-Si layers have such a (100) orientation as a result of the AIC process. From the size of the squares and the lines, we calculated that most defects were formed in the seed layer or at the seed layer-epitaxial layer interface. Beside the epitaxial stacking faults other defects like e.g. dislocation lines crossing the surface were also found.

We performed room-temperature EBIC measurements in a Philips XL 30 system to characterize local electrical defects. Figures $2 \mathrm{a}$ and $2 \mathrm{~b}$ show SEM and EBIC images at room temperature (RT) of an identical area of a solar cell made from a large grained pcSi layer. The solar cell had a diffused n-type emitter. ${ }^{10}$ The topology of the surface 
influences the EBIC image due to the position-dependent generation volume in the pc-Si layers ${ }^{11}$, but the EBIC images clearly show more than only a topology contrast. The same pattern as after defect etching is present, indicating that the defects have a strong recombination activity. The mutual different orientation of the defect lines in both grains of Figure $2 b$ is a consequence of a different rotation around the [100] axes of both (100) grains. Grain boundary contrast was light for low acceleration voltages (e.g. $10 \mathrm{kV}$ in Figure $2 \mathrm{~b})$ but became dark for high $(\sim 20 \mathrm{kV})$ acceleration voltages. This is a consequence of the emitter diffusion which results in deep emitter spikes at grain boundaries due to enhanced diffusion of phosphorus along these grain boundaries. ${ }^{5}$ At low acceleration voltage, the maximum electron-hole generation depth is around $1 \mu \mathrm{m}$ which is comparable to the depth of the emitter spikes at the grain boundaries. The grain boundaries therefore show an increased collection compared to the intra-grain regions. At higher acceleration voltages (e.g. $20 \mathrm{kV}$ ), electron-hole generation extends well below the junction spikes (maximum electron-hole generation depth $\sim 5 \mu \mathrm{m}$ ). In this case recombination at the grain boundaries below the emitter spikes dominates, resulting in a dark EBIC contrast at the grain boundaries. Since large-grained pc-Si layers show a large density of electrically active intra-grain defects and since $V_{o c}$ values of pc-Si solar cells are quasi-independent on the grain size, we believe that intra-grain defects are the major limiting factor for the electrical quality of pc-Si layers today.

We performed CL and spectrum imaging (CLsi) measurements in a JEOL 5800 SEM to obtain more local information about the electrical quality of our pc-Si layers. ${ }^{12}$ Since CL of silicon appears to be similar to photoluminescence excited by above-band-gap 
radiation ${ }^{13}$, sharp dislocation-related peaks (D1-D4) are expected for monocrystalline silicon ${ }^{14}$, while a broad peak is expected for fine-grained polycrystalline silicon with a grain size in the order of $100-300 \mathrm{~nm} .{ }^{15}$ Figure $3 \mathrm{a}$ is a global CL spectrum of a hydrogenated pc-Si layer measured at $50 \mathrm{~K}$ on an area of about $100 \times 100 \mu \mathrm{m}^{2}$, with an ebeam excitation voltage of $10 \mathrm{kV}$ and a current of $5 \mathrm{nA}$. Low acceleration voltages are required to enhance the silicon layer signal compared to the substrate signal. The shape of the spectrum is between that of mono and fine-grained silicon. Next to the phononassisted band-to-band emission, two broad deep-level transitions are present at $0.85 \mathrm{eV}$ and $0.93 \mathrm{eV}$. We note that sharper peaks are expected at temperatures below $50 \mathrm{~K}$. We used spectrum imaging mode (see e.g. ref 12) to investigate the position dependence of the deep level transitions. To make the grains visible before CL spectrum imaging, the layers were defect etched for just a few seconds with the same solution as described above. This short defect etch may have removed some defects/defect complexes at the surface, but this will have had only a minor influence on the measurements since carrier generation also occurs deeper in the layer. Figure $3 b$ is a SEM image of the investigated pc-Si layer, whereas Figure $3 \mathrm{c}$ is the corresponding photoluminescence map showing the dominant deep-level transitions. Although both deep-level transitions simultaneously occur all over the film, the relative intensity of both transitions changes throughout the film. The dominance of a transition was quite uniform in a grain but changed from grain to grain. The recombination behavior seems to be therefore grain dependent.

While the role of impurities remains uncertain, their presence is often linked to D-band luminescence. ${ }^{16,17,18}$ In the layers used for this paper, metal and/or other impurities may 
well be present (e.g. some $\mathrm{Cu}$ traces were found in similar layers). If our CL results can indeed be linked to the presence of metal impurities in our layers, these results suggest that different grains have different impurity concentrations. The reason for this is still unclear. Whether there exists a relation with the grain orientation also still remains an open question. The use of aluminum and e-beam evaporation during seed layer formation results in a process prone to metal contamination. However, we believe that harmful metal contamination is not an intrinsic problem of the AIC seed layer process.

We conclude that the large number of electronically active intra-grain defects found in epitaxially thickened AIC layers is the major reason for the unexpected quasiindependence on grain size of the Voc values of solar cells made from these layers. Besides grain size distribution control, intra-grain quality improvement is therefore very important to obtain thin-film polysilicon layers with good electronic quality. CL measurements showed two broad deep-level transitions at $0.85 \mathrm{eV}$ and $0.93 \mathrm{eV}$, whose relative intensity changed from grain to grain. This changing recombination behavior suggested that different grains have different impurity concentrations.

The authors would like to thank K. Van Nieuwenhuysen for epitaxial layer growth. This work was partly funded by the European Commission under contract 019670 - FP6-ISTIP (ATHLET) and partly performed in the framework of the projects 1.2.16/D2/841 and 1.2.14/PO/841 of the Objective 2 programme for Limburg (Belgium) of the European Regional Development Fund with title "Integrated Material Research for development and application in the automotive sector" 


\section{References}

[1] D. Van Gestel, I. Gordon, L. Carnel, L. R. Pinckney, A. Mayolet, J. D’Haen, G. Beaucarne and J. Poortmans, Amorphous and Polycrystalline Thin-Film Silicon Science and Technology — 2006, Mater. Res. Soc. Symp. Proc. 910, Warrendale, PA, A26-04 (2007)

[2] A. Straub, D. Inns, M. L. Terry, Y. Huang, P. I. Widenborg and A. G. Aberle, Journal of Crystal Growth, 280, Issues 3-4, 385 (2005)

[3] Oliver Nast and Stuart R. Wenham, J. Appl. Phys. 88, 124 (2000)

[4] D. Van Gestel, I. Gordon, L. Carnel, K. Van Nieuwenhuysen, J D’Haen, J. Irigoyen, G. Beaucarne and J. Poortmans, Thin Solid Films, 511 - 512, 35 (2006)

[5] L. Carnel, I. Gordon, D. Van Gestel, G. Beaucarne, J. Poortmans and A. Stesmans, J. Appl. Phys. 100, 063702 (2006)

[6] Mitsuru Imaizumi, Tadashi Ito, Masafumi Yamaguchi and Kyojiro Kaneko, J. Appl. Phys. 81, 7635 (1997)

[7] Thomas Kieliba, Stephan Riepe and Wilhelm Warta, J. Appl. Phys, 100, 063706 (2006)

[8] L. Carnel, H.F.W. Dekkers, I. Gordon, D. Van Gestel, K. Van Nieuwenhuysen, G. Beaucarne and J. Poortmans, IEEE electron device letters, 27, 163 (2006)

[9] D. G. Schimmel, J. Electrochem. Soc., 126, 479 (1979)

[10] I. Gordon, K. Van Nieuwenhuysen, L. Carnel, D. Van Gestel, G. Beaucarne and J. Poortmans, Thin Solid Films, 511 - 512, 608 (2006) 
[11] A.B. Sproul, T. Puzzer and R.B. Bergmann, Proceedings of the $2^{\text {nd }}$ World

Conference on Photovoltaic Solar Energy Conversion, Vienna, 1355, 6-10 July 1998

ISBN 92-828-5419-1

[12] M.J. Romero, K. Ramanathan, M.A. Contreras, M.M. Al-Jassim, R. Noufi and P.

Scheldon, Appl. Phys. Lett. 83, 4770 (2003)

[13] Gordon Davies, Physics reports, 176 (3-4), 83 (1989)

[14] R. Sauer, J. Weber and J. Stolz, Appl. Phys. A 36, 1 (1985)

[15] A.U. Savchouk, S. Ostapenko, G. Nowak, J. Lagowski and L. Jastrzebski, Appl.

Phys. Lett. 67, 82 (1995)

[16] V. Higgs, T. Q. Zhou and G. A. Rozgonyi, Materials Science and Engineering, B24, 48 (1994)

[17] A.J. Kenyon, E.A. Steinman, C.W. Pitt, D.E. Hole and V.I. Vdovin, J. Phys.:

Condens. Matter 15, S2843 (2003)

[18] T. Sekiguchi and K. Sumino, J. Appl Phys. 79, 3253 (1996) 
Figure 1

Top view SEM picture of a defect etched polycrystalline silicon layer inside a grain with a high density of intra-grain defects (no grain boundaries are present in the image).

Figure 2

a) Top view SEM and b) Top view EBIC image at RT of two poly-crystalline silicon grains. Electrically active intra-grain defects are visible with a pattern comparable to that observed in the defect etched layer (see figure 1). Due to the difference in orientation of the perpendicular defect lines the difference in orientation of both grains is visible.

Figure 3

a) Global CL spectrum of a polycrystalline-silicon layer obtained at $50 \mathrm{~K}$ on an area of 100x100 $\mu \mathrm{m}^{2}$. The peak positions of two Gaussian functions fitted to the spectrum for energies lower than the bandgap are located at $0.85 \mathrm{eV}$ and $0.93 \mathrm{eV} . \mathrm{b}$ ) Top view SEM image of a polished and slightly defect-etched polycrystalline-silicon layer. c) Photon energy map of the same area for the two deep-level transitions found in the global CL spectrum. 